\title{
Television Meets Facebook: The Correlation between TV Ratings and Social Media
}

\author{
Mei-Hua Cheng1, Yi-Chen $\mathrm{Wu}^{2}$, Ming-Chih Chen' \\ ${ }^{1}$ Graduate Institute of Business Administration, College of Management, Fu Jen Catholic \\ University, Taiwan \\ ${ }^{2}$ College of Communication at Fu Jen Catholic University, Taiwan \\ Email: cmh82728@gmail.com
}

Received 21 February 2016; accepted 22 March 2016; published 25 March 2016

Copyright (C) 2016 by authors and Scientific Research Publishing Inc.

This work is licensed under the Creative Commons Attribution International License (CC BY). http://creativecommons.org/licenses/by/4.0/

(c) (i) Open Access

\begin{abstract}
This study examines the relationship between social media site Facebook and TV ratings drawing from audience factors of integration model of audience behavior. Based on context of Taiwan television network programs, this study collected measures for Facebook likes, shares, comments, posts for three genres of television shows and their Nielsen ratings over a period of eleven weeks, resulting in the size of sample more than 130 observations. This study applied multiple regression models and determined that the key social media measures correlate with TV ratings. In essence, TV shows with higher number of posts and engagement are likely to relate to higher ratings, special in drama shows. Subsequently, this study constructed the TV prediction models with measures for Facebook via SVR. The results suggested that prediction models are a good forecasting of which MAPE was between 10\% - 20\%, even less than 10\%. This implies that TV network should be motivated to invest in social media and engage their audience and analysts can use social media as a mechanism of exante forecasting.
\end{abstract}

\section{Keywords}

Social Media, TV Ratings, Facebook, Audience Measurement

\section{Introduction}

Social media has been on the rise for years. From Twitter and Facebook, to Instagram, the social media world has grown. While the popularity of apps has skyrocketed in recent years, new media have made a wide range of platforms and content choice. Media consumption seems to have become anywhere, anytime. By making live streams, social TV, mobile, these apps turn audience into “active audience” [1]. The social media platform al- 
lows fans to directly help to promote and encourage the growth of audience base. TV stations communicate with audiences by these technologic tools special in social media such as Facebook, Twitter, Weibo, Line etc. Nowadays, audience discussion in online forums, Facebook and chat rooms can be gathered, aggregated, analyzed immediately. Social media transformed traditional broadcasting norms.

Social media introduce a new approach for TV viewers to interact with the TV shows as well as with other viewers about the shows. The likes, shares, comments of Facebook allow viewers to share their opinions and to show support for their favorite TV shows. In a way it enables fans to participate in discussion whilst watching the shows on TV. Facebook is a social networking sites launched in 2004, as of this writing, it claims 1.55 billion active users, and is still growing [2]. This social media is the most popular in Taiwan, which monthly active users were 16 million. Facebook users form networks by indicating to the system which other users are their friends. In 2007, Facebook released an open API that allows third parties to develop applications that dock into the Facebook user interface. Once granted access to a user's personal data, a Facebook application can aggregate this data across multiple users.

According to Nielsen's report “The Relationship between Social Media Buzz and TV Ratings”, online buzz is in aligned with TV ratings. A 9\% 14\% increase in buzz volume corresponds to a 1\% increase in ratings [3]. Nielsen Media Company measures audience via sample-based methodology, which is Nielsen ratings. Under the new media circumstances, people's view habits are changing and those who are post broadcast viewers are not counted. It implies that viewer's information may not be as accurate as before. However, this media research company also launched the Nielsen Twitter TV Ratings in 2013, which Nielsen Twitter TV Ratings complete the picture by measuring both Twitter TV-specific activity (Authors, Tweets) and reach (Unique Audience, Impressions). Nielsen announced that Nielsen Twitter TV Ratings “will become Nielsen’s 'Social Content Ratings"” including Facebook conversation, and this indicator will be the first solution to measure aggregate-level program-related conversation on Facebook and Twitter, including posts shared with friends and family, with followers, and publicly. The expanded ratings are slated for commercial availability in the first half of 2016 and will be made available in all markets where Nielsen Twitter TV Ratings are currently available (Australia, Italy, Mexico and U.S.) [4] [5]. Other media measurement companies and institutes have tried developed many metrics of TV ratings such as share-of voice, content power ratings and Hi score which developed by Harmony institute [6] [7].

The industry researchers and academic researchers have more rigorously explored the relationship between social media and media impact special in TV and movie box office sales. We also found that TV ratings correlated with Facebook posts from a practical case which is an entertainment show in Taiwan [8]. In spite of that, a much debated issue is whether social buzz gooses TV ratings? This study put forward the following questions in relation to TV ratings and social media: How does audience engagement in social media directly correlate with the TV program's performance? How does the performance of TV program relate to the posts from the official account? Does engaging with audiences help increasing ratings? The objective of this study was to collect and analyze the data from social media, special in Facebook in examining the relationship between social media activities and TV ratings. In principle, this study tried to identify key variables of social media activities that relate to TV show performance and ratings prediction model.

\section{Literature Review}

\subsection{Media Choice Theory}

TV viewing is a type of herd phenomenon [9] [10], where people gather in front of the TV to watch shows and discuss their content. After the popularization of the TV and its introduction to the living room or bedroom, TV viewing gradually evolved into an individualized viewing behavior. At this stage, audience viewing of TV content was a one-way communication. As technology improved and the number of investors increased, TV channels rapidly increased from two to three in the past to hundreds or even thousands. Viewers enjoyed had a vast number of choices, and the operation of channel content transitioned from integrated channels (including news, variety shows, drama, and other types) to single-type specialist channels (e.g., 24-hour news channel, movie channel, children’s channel). It called a linear media environment except there were many channels which of audience's choice.

Webster published an article "A Theory of Television Program Choice" in 1983, which stated that within a linear media environment, audience viewing behavior is influenced by factors such as limited time, personal 
preferences, and program type provided by the TV station; in other words, audience viewing behavior is influenced by audience availability and content exposure [11]. Latterly, Webster applied the "theory of structuration" proposed by Giddens (1984) to explain the duality between agents (audiences) and structure (media, such as TV channels). Webster (2013) modified the "theory of television program choice" based on internet factors to construct "an integrated model of audience behavior". Webster's model explored the influence of audience and media factors on content exposure, of which (1) audience factors include structural potential audience/available audience, individual preferences, group vs solitary use, awareness of options, and social network; (2) media factors include structural coverage, content options, recommender systems, individual technology owned, subscriptions, and repertoire; (3) the measurement indices of content exposure included gross measurements (including average ratings, market share, impressions, views, and total sale) and cumulative measurements (including cumulative ratings, reach, unique visitors, frequency, and audience duplication) (Figure 1). There also are cause-andeffect relationships among the factors within the box.

In addition, the influential factors include technological development, programs, services, strategies, culture, interests, expectations, and habits [11]. Webster emphasized a winner-takes-all result in the internet era, as well as stated that social media and the recommender system together intensify the herd phenomenon in the audience. From a personal perspective, the audience can view programs through internet service subscriptions and from different devices (TV, tablet computer, smartphone), which could change the pattern of TV different content exposure and audience repertoire. He pointed out that digital media extend traditional face-to-face encounters to larger virtual networks, amplifying the effects of people's preferences and offering people a host of new tools to cope with their options. The model is simple but fruitful. It acknowledges the social situation and content as flow.

\subsection{TV Audience Measures}

General measurements of how audiences approach media and what content to consume can be split into two categories following their origin of production. One source of origin is professional audience researches belong to industry, business and practice that is continuously producing accounts of audience behavior to support everyday business while the other is the audience researches produced within academia [11].

Historically, measurement systems have been tools of commercially supported media. Ratings services made it possible for television and web to respond and profit from their audiences. There are two parallel, potentially intersecting and development tracks. The traditional approach to measuring and valuing TV audience is based on audiences' exposure to TV shows, such as Nielsen's ratings, Arbitron for radio etc. The other approach is engagement-based methods which are beyond audiences' exposure, for example, tweets-based ratings, identifying online comments made at specific moments during individual program, aggregating total views and engagement for TV shows on-air, online and on mobile platforms.

Social media presents a new research context that is nascent, timely, high volume, and rapid. In addition to, researchers investigated how social media activities relate to TV ratings. Wakamiya, Lee and Sumiya proposed a model for measuring TV ratings based on tweets as crowd voices and designed a Twitter-based rating platform [12]. They developed a method for computing the relevance between tweets and TV ratings. Mhaisgawa and Gir studied that predictive analytics with Twitter based TV ratings [13]. They suggested that relevant tweets which were twitted by people watching the TV show do calculate TV ratings. In Taiwan, the "Social Intelligence Analysis Service Platform” project of the Institute for Information Industry which is subsidized by the Ministry of Economy Affairs (Taiwan) aggregated TV dramas' word-of-mouth on Facebook (likes, shares, posts, comments) and applied Back-propagation Network to predict TV ratings [14] [15]. This study suggested that the data from Facebook fan pages apply to prediction of TV ratings. Oh, Sasser, and Almahmoud (2015) examined volume and valence of social media surrounding super bowl advertisements and concluded that both have positive correlation with ratings [16]. A social media analytics examined app and the Facebook of the context of television reality-entertainment show and suggested that audience more actively engages with the TV show, more positively affects TV ratings [8].

In digital media environment, media use to be tractable. We can focus on micro-level phenomena and identify patterns of individuals. The amount of data collected by servers powers the digital networks, especially in social media. As we known, ratings research has measured exposures to media. In this digital media era, engagement could be a valuable metric as exposure. Thus, most of the ratings measurement tried to measure exposures and predict a "post-exposure audience marketplace which produces a "basket of currencies" [9]. The "integrated model of audience behavior" reflects all of micro-level and macro-level phenomena. The model presented in 
Figure 1 tries to explain exposure to media which is the central component of the model via media factors and audience factors. Based on the integrated model of audience behavior, this study focused on the audience factors special in individual. This research tried to examine audience factors of the determine ratings and the prediction model with engagement.

\section{Methodology}

\subsection{Social Media Framework}

This study uses the social media analytics framework adapted from Oh et al. [16] [17], a four-stage process. The abbreviation of CUP involves the process of capture, understand and present. The framework is as following: (1) data collection, (2) pre-processing, (3) features selection, (4) analysis (Figure 2). This research design a simple approach of account for Facebook pertaining to respective TV shows, and collecting the data belong to fan page of TV show (such as likes, comments, shares, posts etc.). These messages were the pre-processed and selected features. Then, models were created and analyzed.

\subsection{Data Collection}

The first step in this study process was data collection. We collected TV ratings within March 26, 2015 and June 8, 2015. Shows selected for analysis were the top 60 of ratings. The Nielsen Media, Taiwan provided the TV rating which is the major measurement of TV ratings. The most popular shows were entertainment, political talk-show, news and drama. The news programs were excluded from the analysis. In addition to, this study sorted out TV ratings two groups: (1) TVR-all demographics group (above 4 years old) and (2) TVR-15 (between 15 and 44 years old) demographics group. Following the approach of web mining, these account names were then inserted into the PHP scripts to search for relevant FB profiles via FB graph API. These scripts run daily in broadcasting search query requests.

\subsection{Pre-Processing}

The second task was pre-processing. This study prepared the dataset involved removing data which were un-relevant to the respective accounts. Due to limited availability of fan page on FB, only 11 TV shows were selected for the final analysis. Table 1 lists the TV shows.

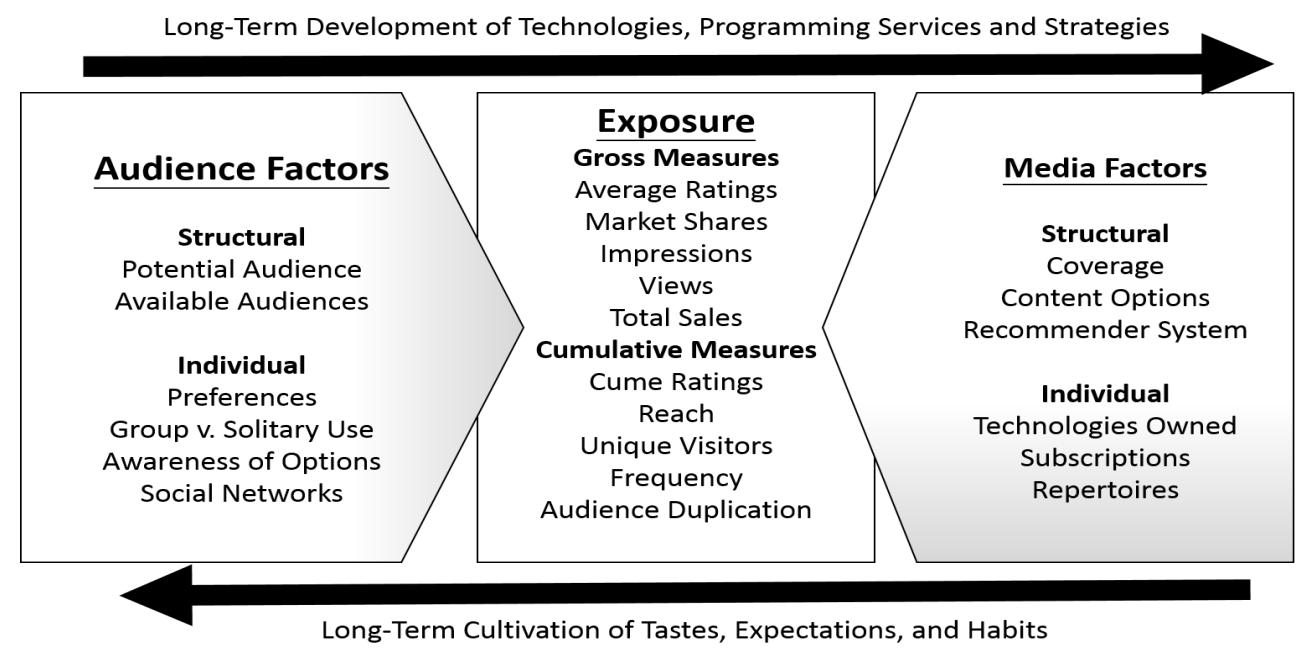

Figure 1. A integration model of audience behavior.

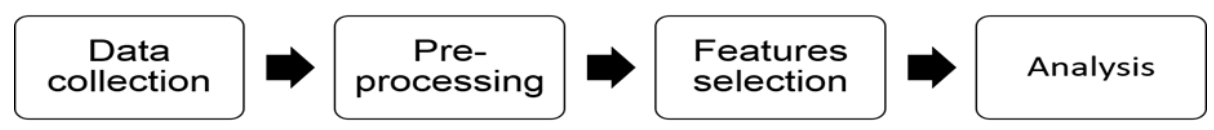

Figure 2. Social media framework. 
Table 1. The list of TV shows which analyzed.

\begin{tabular}{ll}
\hline Genre & Name of program \\
Drama & 世間情, 嫁妝, 戲說台灣, 聽見幸福 \\
Political talk-show & 新聞追追追, 新聞龍捲風, 新台灣加油, 關鍵時刻 \\
Entertainment & 明日之星, 康熙來了, 熱門大綜㙯 \\
\hline
\end{tabular}

\subsection{Features Selection}

The third stage involved extracting relevant variables for the selected TV shows. These variables consisted of the social media measures of FB. The social media measures of FB count of posts for each TV shows, the FB number of likes, the number of comments, the number of shares and the text of comments (see the variables in Table 2).

\subsection{Analysis}

The fourth task was to analyze the extracted variables in testing the multiple regression model and multiple correlation. Finally, this study tried to construct a prediction model via SVR. Section 4 provides more details description of this process.

\section{Results}

This study examined the relationship between social media activities surrounding TV shows and TV ratings. Data downloaded via R software from Facebook, it suggested that engagement (likes, shares and comments) and ratings of the drama shows were higher than others (Table 3). TV ratings of political talk shows were the lowest which were major programs of news channels on the prime times (20:00 - 24:00) in Taiwan.

\subsection{Multiple Regression Model and Multiple Correlation}

\section{1). Correlation}

Table 4, Table 5 and Table 6 showed the correlation matrices for the main variables for this study. The correlation matrices were categorized into 3 groups: drama, entertainment and political talk shows. The results showed that there was weak correlation between TV ratings and social media measures. For example, drama shows, the TVR-all demographics, showed a negative correlation between ratings and social media measures. The TVR-15 demographics of drama shows appeared that there was a weakly positive correlation between ratings and social media measure. However, the results appeared that there a positively significant correlation within social media measures.

2). Multiple Regression

This study examined relationship between social media measures and TV ratings via multiple regression models: 1) drama for TVR-all demographics group and TVR-15 demographics group, 2) entertainment shows for TVR-all demographics group and TVR-15 demographics group, 3) political talk shows for TVR-all demographics group and TVR-15 demographics group. The general model is outlines below while the results are shown in Table 7.

$$
\text { Tvr } i=\beta 0 * \text { intercept }+\beta 1 * \text { likes } i+\beta 2 * \text { comments } i+\beta 3 * \text { shares } i+\beta 4 * \text { posts } i+\beta 5 * \operatorname{sem} i+e i
$$

The equation (1), $\beta 0$ is intercept, e $I$ is the error term, TV R $i$ is TVR-all $i$ or TVR-15 $i$ and $i$ is a daily observation for TV shows.

The multi-egression models suggested that there is a relationship between social media activities with ratings. The estimation results for these models showed that posts which were posted from TV show's FB account were associated with TV ratings. There told an interesting story. The model of the political talk differed from others and shows implied that posts were negatively significant in relation with ratings. For example, political talk shows, the results showed negative relationship between posts and TVR-all demographics $\left(\beta 4=-0.008408^{* * *}\right)$, although R-squared (0.0915) was weak. However, TVR-all demographics for drama and entertainment, the results showed that posts were positively related with ratings (drama: $\beta 4=0.07282^{*}$, entertainment: $\beta 4=$ $\left.0.0747^{* * *}\right)$. Both of drama and entertainment, TVR-all demographics, R-squared value were higher than political talk show (drama: R-squared $=0.3908$, entertainment: $\mathrm{R}$-squared $=0.7684$ ). The estimation results for 
Table 2. The list of variables.

\begin{tabular}{lll}
\hline Variable & Description \\
\hline Dependent & TVR & $\begin{array}{l}\text { TV ratings: TVR-all (average TVR of all age which is above } 4 \text { years old), TVR-15 } \\
\text { (average TVR of 15 - 44 years old) } \\
\text { The number of likes for fan page on FB/episode }\end{array}$ \\
Comments & The number of comments for fan page on FB/episode \\
Independent & Shares & The number of shares for fan page on FB/episode \\
& Posts & The number of post for fan page on FB/episode \\
& Sem & Sentiment scores/episode
\end{tabular}

Table 3. List of data (FB \& TV ratings).

\begin{tabular}{cccccccc}
\hline Genre & Likes & Comments & Shares & Posts & Sem & TVR-all & TVR-15 \\
Drama & $7,463,409$ & 111,370 & 35,385 & 1244 & 0.0230533 & 3.52 & 2.09 \\
Entertainment & 872,312 & 21,827 & 10,647 & 1018 & 0.0481502 & 1.10 \\
Political talk-show & 357,491 & 24,923 & 30,554 & 1198 & -0.0382287 & 0.71 \\
\hline
\end{tabular}

Table 4. Correlation matrix for drama shows.

\begin{tabular}{|c|c|c|c|c|c|c|c|}
\hline & Likes & Comments & Shares & Posts & Sem & TVR-all & TVR-15 \\
\hline Likes & 1 & $0.988^{* *}$ & $0.996^{* *}$ & $0.986^{* *}$ & 0.042 & -0.074 & 0.043 \\
\hline Comments & $0.988^{* *}$ & 1 & $0.997^{* *}$ & $0.998^{* *}$ & 0.019 & 0.000 & 0.048 \\
\hline Shares & $0.996^{* *}$ & $0.997^{* *}$ & 1 & $0.994^{* *}$ & 0.032 & -0.027 & 0.048 \\
\hline Posts & $0.986^{* *}$ & $0.998^{* *}$ & $0.994^{* *}$ & 1 & 0.016 & -0.020 & 0.031 \\
\hline Sem & 0.042 & 0.019 & 0.032 & 0.016 & 1 & -0.051 & -0.035 \\
\hline TVR-all & -0.074 & 0.000 & -0.027 & -0.020 & -0.051 & 1 & $0.779^{* *}$ \\
\hline TVR-15 & 0.043 & 0.048 & 0.048 & 0.031 & -0.035 & $0.779^{* *}$ & 1 \\
\hline
\end{tabular}

signif. Code: 0.001 “**», 0.01 “*”.

Table 5. Correlation matrix for entertainment shows.

\begin{tabular}{|c|c|c|c|c|c|c|c|}
\hline & Likes & Comments & Shares & Posts & Sem & TVR-all & TVR-15 \\
\hline Likes & 1 & $0.994^{* *}$ & $0.993^{* *}$ & $0.995^{* *}$ & 0.022 & 0.015 & 0.013 \\
\hline Comments & $0.994^{* *}$ & 1 & $0.995^{* *}$ & $0.992^{* *}$ & 0.016 & 0.015 & 0.007 \\
\hline Shares & $0.993^{* *}$ & $0.995^{* *}$ & 1 & $0.988^{* *}$ & 0.005 & -0.010 & -0.003 \\
\hline Posts & $0.995^{* *}$ & $0.992^{* *}$ & $0.988^{* *}$ & 1 & 0.060 & 0.088 & 0.043 \\
\hline Sem & 0.022 & 0.016 & 0.005 & 0.060 & 1 & $0.507^{* *}$ & $0.194^{*}$ \\
\hline TVR-all & 0.015 & 0.015 & -0.010 & 0.088 & $0.507^{* *}$ & 1 & $0.534^{* *}$ \\
\hline TVR-15 & 0.013 & 0.007 & -0.003 & 0.043 & $0.194^{*}$ & $0.534^{* *}$ & 1 \\
\hline
\end{tabular}

signif. Code: 0.001 “**”, 0.01 “*”.

Table 6. Correlation matrix for political talk shows.

\begin{tabular}{|c|c|c|c|c|c|c|c|}
\hline & Likes & Comments & Shares & Posts & Sem & TVR-all & TVR-15 \\
\hline Likes & 1 & $0.998^{* *}$ & $0.876^{* *}$ & $0.996^{* *}$ & -0.011 & -0.003 & 0.056 \\
\hline Comments & $0.998^{* *}$ & 1 & $0.875^{* *}$ & $0.996^{* *}$ & -0.015 & -0.005 & 0.042 \\
\hline Shares & $0.876^{* *}$ & $0.875^{* *}$ & 1 & $0.868^{* *}$ & -0.033 & -0.011 & 0.053 \\
\hline Posts & $0.996^{* *}$ & $0.996^{* *}$ & $0.868^{* *}$ & 1 & -0.011 & -0.020 & 0.011 \\
\hline Sem & -0.011 & -0.015 & -0.033 & -0.011 & 1 & 0.004 & -0.103 \\
\hline TVR-all & -0.003 & -0.005 & -0.011 & -0.020 & 0.004 & 1 & 0.106 \\
\hline TVR-15 & 0.056 & 0.042 & 0.053 & 0.011 & -0.103 & 0.106 & 1 \\
\hline
\end{tabular}

signif. Code: 0.001 “**”, 0.01 “*”. 
Table 7. Multiple regression of TV shows ratings on social media measures.

\begin{tabular}{|c|c|c|c|c|c|c|}
\hline & \multicolumn{2}{|c|}{ Drama } & \multicolumn{2}{|c|}{ Entertainment } & \multicolumn{2}{|c|}{ Political talk-show } \\
\hline & TVR-all & TVR-15 & TVR-all & TVR-15 & TVR-all & TVR-15 \\
\hline (intercept) & $1.955^{* * *}$ & $1.395^{* * *}$ & $0.7544^{* * *}$ & $1.111^{* * *}$ & $0.7373^{* * *}$ & $0.4399 * * *$ \\
\hline likes & $-0.0000188 * * *$ & $-0.00001025^{* * *}$ & $-0.000036^{* * *}$ & -0.0000014 & 0.000004729 & $0.00003384 * *$ \\
\hline comments & $0.002003^{* * *}$ & $0.0004939 * *$ & -0.000258 & -0.0000477 & 0.00006654 & -0.00007438 \\
\hline shares & 0.00004105 & 0.00044646 & -0.0000041 & -0.0000169 & -0.00000376 & -0.00000520 \\
\hline posts & $0.07282^{*}$ & $0.0101 * * *$ & $0.0747 * * *$ & $0.01124 * * *$ & $-0.008408 * * *$ & $-0.002385^{*}$ \\
\hline sem. & 0.1374 & -0.6733 & 0.8439 & -0.3686 & -0.06007 & -0.08918 \\
\hline R-squared & 0.3908 & 0.4406 & 0.7684 & 0.1808 & 0.0915 & 0.3764 \\
\hline $\begin{array}{c}\text { adjusted } \\
\text { R-squared }\end{array}$ & 0.3766 & 0.4233 & 0.7589 & 0.1472 & 0.0710 & 0.3627 \\
\hline $\mathrm{F}$ & 27.58 & 25.52 & 80.96 & 5.386 & 4.548 & 66.267 \\
\hline$p$-value & $2.2 e^{-16}$ & $2.2 \mathrm{e}-16$ & $2.2 \mathrm{e}-16$ & 0.00016 & 0.0005685 & $2.2 e^{-16}$ \\
\hline Mean VIF & 20.228 & 23.042 & 1.747 & 1.747 & 1.951 & 1.661 \\
\hline
\end{tabular}

signif. Code: 0 “***”, 0.001 “**”, 0.01 “*”, $\beta=$ estimate coefficients.

drama presented also showed the social media measures, likes and comments were associated with ratings (TVR-all: $\beta 1=-0.0000188^{* * *}, \beta 2=0.002003^{* * *}$; TVR-15: $\beta 1=-0.00001025^{* * *}, \beta 2=0.0004939 * *$ ). The social media measure, shares which was a considered of topic in TV industry, the estimation results showed a weak relation with ratings. The mean variance inflation factor (VIF) for entertainment models and political models were lower than 10 indicated that multicollinearity is a concern for these models. For drama models, the multicollinearity existed because of VIF greater than 10.

\subsection{SVR}

In order to create a SVR model with R software, this study tried to construct a TV ratings prediction model. The data set were split into 2 parts: training set (70\% of data) and test set (30\% of data), in order to obtain an unbiased estimation of the accuracy. Table 8 and Table 9 show that the results for SVR. According to MAPE for model evaluation based on Lewis (1982), if MAPE calculated value is less than 10\%, it is interpreted as excellent accurate forecasting, between $10 \%$ - 20\% good forecasting, between $20 \%$ - 50\% acceptable forecasting and over 50\% inaccurate forecasting [18]. The results showed that MAPE value for all of the models is between $10 \%$ - 20\%, it appears that prediction models are good forecasting. Figure 3 showed the comparison of real ratings and forecasting ratings for drama.

\section{Discussion and Conclusion}

Based on Webster's model “an integrated model of audience behavior” which is trying to explain the exposure to media in the new media environment, we were interested in audience factors special in individual-level factor: social networks. The model suggested that audience behavior was influenced by many things [10]. This study began the process of thinking the individual-level factors on the audience of the model. We examined the relationship between TV ratings and the social media measures which are FB likes, FB comments, FB shares, FB posts and even sentiment scores.

Many studies have a similar conclusion that social media play an important role in attracting audience, the higher the audience engagement in social media such as FB likes, tweets, the higher the ratings. From this study, these regression models found correlation between social media FB metrics with TV ratings, and also, the results showed that the social media metrics could explain a certain percentage of the variability in TV ratings. Table 7 shows that FB posts which were posted by TV show official accounts significantly affect TV ratings ( $p$-value $>0.01$ and higher estimate coefficients). It means that active official accounts are responsible for generating the social media buzz surrounding their shows. These results answered to our question: How does the 
Table 8. SVR of TV shows ratings for all age demographics.

\begin{tabular}{ccccccc}
\hline & \multicolumn{2}{c}{ Drama } & \multicolumn{2}{c}{ Entertainment } & \multicolumn{2}{c}{ Political talk show } \\
\hline & Train & Test & Train & Test & Train & Test \\
Gamma & 1 & 1 & 0.0625 & 0.0625 & 4 & 4 \\
Cost & 16 & 16 & 64 & 64 & 1 & 1 \\
MAD & 0.184299 & 0.4595177 & 0.1026873 & 0.1913041 & 0.06220315 & 0.09290724 \\
MSE & 0.05506303 & 0.4275272 & 0.04950691 & 0.06275968 & 0.009178832 & 0.01502102 \\
MAPE & 5.652275 & 13.12195 & 11.21722 & 18.5534 & 8.608339 & 12.90695 \\
\hline
\end{tabular}

Table 9. SVR of TV shows ratings for 15 - 44 years old demographics.

\begin{tabular}{cccccc}
\hline & \multicolumn{2}{c}{ Drama } & \multicolumn{2}{c}{ Entertainment } & \multicolumn{2}{c}{ Political talk show } \\
\hline & Train & Test & Train & Test & Train \\
Gamma & 2 & 2 & 2 & 2 & 0.5 \\
Cost & 4 & 4 & 0.12 & 0.12 & 4 \\
MAD & 0.1830403 & 0.3291978 & 0.1526722 & 0.1641403 & 0.04131621 \\
MSE & 0.0736489 & 0.1787382 & 0.04228849 & 0.03833975 & 0.003923453 \\
MAPE & 10.24794 & 17.97146 & 14.65164 & 13.80516 & 0.07572303 \\
\hline
\end{tabular}

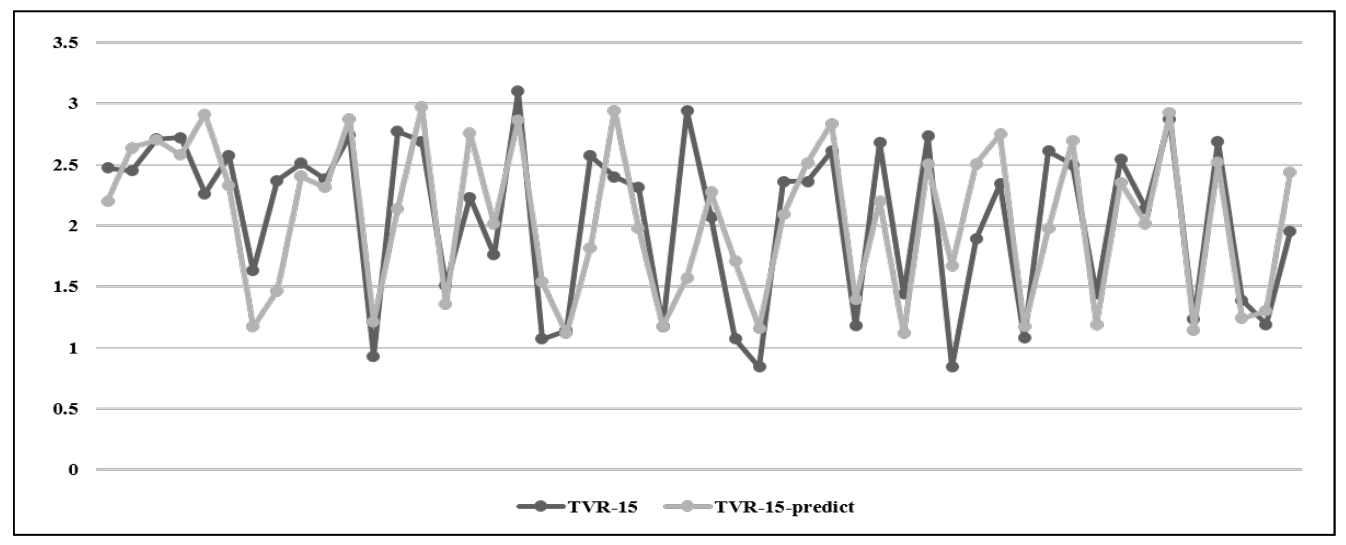

TVR-15: real ratings, TVR-15-predict: prediction based on SVR.

Figure 3. The prediction model of drama, TVR-15 demographics.

performance of TV program relate to the posts from the official account? FB posts are indeed a relevant factor of TV ratings.

As aforementioned question which is "How does audience engagement in social media directly correlate with the TV program's performance?”, Table 7 shows that the metrics of engagement of which FB likes, FB comments are associated with TV ratings. This result confirmed that audience engagement in social media directly correlates with the TV program's performance. For example, the metrics of engagement have significant effect on drama shows (p-value $>0.01$ ). Additionally, the TV ratings prediction models of SVR are good forecasts of which MAPE was between $10 \%$ - 20\%, even less than $10 \%$. As a result, official accounts should post often and engage their audiences in an effort to attract new audience and keep their activities around the TV shows. It hints that TV network and producers should be motivated to invest in social media and engage their audience.

This study concludes there is a certain relationship between TV ratings and FB measures, also implying that FB measures could be the indicators of TV ratings prediction. Furthermore, instead of having waiting Nielsen TV ratings until the end of the period to determine the performance of a TV show, the analysts can use social media as a mechanism of ex ante forecasting [17]. Based on this conclusion, we urge managers to consider the 
design of engagement plan in their social media strategies. This study contributes in comparing the genres of TV programs, not programs. However, some of them require further examination and amplification. A limitation in the current study lies in having few TV ratings which are difficult to get the reports in Taiwan and only one social media-Facebook. For the future research, we may extend the current analysis with surveyed data and apply with other methodologies.

\section{Acknowledgements}

We would like to thank Professor Shia, Ben-Chang, for comments and suggestions on the manuscript.

\section{References}

[1] Napoli, P.M. (2014) Measuring Media Impact an Overview of the Field. Lear Center's Media Impact Project. http://www.mediaimpactproject.org

[2] Facebook Reports Third Quarter 2015 Results (2015) http://investor.fb.com/releasedetail.cfm?ReleaseID=940609

[3] Subramanyan, R. (2011) The Relationship Between Social Media Buzz and TV Ratings. Nielsen Media and Entertainment. http://www.nielsen.com/us/en/insights/news/2011/the-relationship-between-social-media-buzz-and-tv-ratings.html

[4] Nielsen (2013) Nielsen Launches’ Nielsen Twitter TV Ratings. http://www.nielsen.com/ug/en/press-room/2013/nielsen-launches-nielsen-twitter-tv-ratings.html

[5] Nielsen (2016) Nielsen to Launch "Social Content Ratings” with Measurement across Twitter and Facebook. http://www.nielsen.com/us/en/press-room/2016/nielsen-to-launch-social-content-ratings-with-measurement-across-twit ter-and-facebook.html

[6] Harmony Institute (2013) A Better Way to Analyze Social Impact. http://harmony-institute.org/therippleeffect/2013/11/15/a-better-way-to-analyze-social-impact/

[7] Harmony Institute (2013) Sharing Influence: Understanding the Influence of Entertainment in Online Social Networks. http://harmony-institute.org/wp-content/uploads/2013/07/Sharing Influence HarmonyInstitute.pdf

[8] Cheng, M.H., Wu, Y.C., Chen, M.C., Hsieh, B.Y. and Chen, C.C. (2015) A Study of Correlation TV Ratings and Social Media. JDA, 10, 55-58.

[9] Napoli, P.M. (2011) Audience Evolution: Technology and the Transformation of Media Audience. Columbia University Press, New York.

[10] Webster, J.G. (2014) The Marketplace of Attention: How Audiences Take Shape in a Digital Age. The MIT Press, Cambridge, MA, London, England.

[11] Webster, J.G., Phalen, P.F. and Lichty, L.W. (2014) Ratings Analysis: Audience Measurement and Analytics. 4th Edition, Routledge, UK.

[12] Wakamuya, S., Lee, R. and Sumiya, K. (2011) Towards Better TV Viewing Rates: Exploiting Crowd’s Media Life Logs over Twitter for TV Rating. ICUIMC'11, Seoul, Korea, February 2011, Article No. 39. http://dx.doi.org/10.1145/1968613.1968661

[13] Mhaisgawali, A. and Giri, N. (2014) Detailed Descriptive and Predictive Analytics with Twitter Based TV Ratings. IJCAT, 1, No. 4,

[14] Hsie, W.T., Chou, S.T., Cheng, Y.H. and Wu, C.M. (2013) Predicting TV Audience Rating with Social Media. IJCNLP, Workshop on Natural Language Processing for Social Media (Social NLP), Nagoya, October 2013, 1-5.

[15] Huang, Y.Y., Yen, Y. A., Ku, T.W. and Lin, S.D. (2014) A Weight-Sharing Gaussian Process Model Using WebBased Information for Audience Rating Prediction. Technologies and Applications of Artificial Intelligence Lecture Notes in Computer Science, 19th International Conference, TAAI 1014, Taipei, 21-23 November 2014, 198-208. http://dx.doi.org/10.1007/978-3-319-13987-6_19

[16] Oh, C., Sasser, S. and Almahmoud, S. (2015) Social Media Analytics Framework: The Case of Twitter and Super Bowl Ads. Journal of Information Technology Management, 26, No.1

[17] Oh, C. and Yergeau, S. Social Capital, Social Media, and TV Ratings. International Journal of Business Information Systems.

[18] Lewis, C.D. (1982) International and Business Forecasting Methods. Butterworths, London. 